\title{
Retraction Note: The AtCCX1 transporter mediates salinity tolerance in both Arabidopsis and yeast
}

Zhiyuan Chen · Yongjun Wu $\cdot$ Lijun Di •

Guodong Wang $\cdot$ Yufang Shen

Published online: 21 June 2012

(C) Springer Science+Business Media B.V. 2012

Retraction to: Plant Cell Tiss Organ Cult (2012)

109:91-99

DOI 10.1007/s11240-011-0077-6

The authors of the article entitled "The AtCCX1 transporter mediates salinity tolerance in both Arabidopsis and yeast," published in PCTOC, 109:91-99, wish to retract this publication due to duplication of partial data from a formerly published article, which is also not cited.

Yongjun Wu (Corresponding author) and Zhiyuan Chen (Senior author).

The online version of the original article can be found under doi: 10.1007/s11240-011-0077-6.

Z. Chen · Y. Wu $(\bowtie)$

College of Life Sciences, Northwest A\&F University,

Yangling 712100, Shaanxi, China

e-mail: nwsuafdrought@yahoo.com.cn

Z. Chen · L. Di · G. Wang

College of Sciences, Northwest A\&F University,

Yangling 712100, Shaanxi, China

\section{Y. Shen}

Institute of Soil and Water Conservation, Chinese Academy of Sciences \& Ministry of Water Resources, Yangling 712100,

Shaanxi, China 